\title{
Soroprevalência da infecção por lentivírus de pequenos ruminantes em abatedouros do estado de Pernambuco, Brasil
}

\author{
Seroprevalence small ruminant lentiviruses \\ in the state of Pernambuco slaughterhouses, Brazil
}

\author{
Elialdo Xavier Melo', Erivânia Camelo de Almeida', Kátia Maria Nascimento Mendonça', \\ Sérgio Alves do Nascimento ${ }^{2}$, Jean Carlos Ramos Silva², Maria Fernanda Vianna Marvulo ${ }^{3}$, \\ Huber Rizzo ${ }^{2 *}$, Roberto Soares de Castro ${ }^{2}$
}

RESUMO: A soroprevalência da infecção por lentivírus de pequenos ruminantes (LVPR) foi determinada em amostras de soros sanguíneos de caprinos e ovinos de aptidáo cárnea provenientes de abatedouros de dez municípios do estado de Pernambuco, Brasil. O diagnóstico sorológico ocorreu por meio da imunodifusão em gel de agarose (micro-IDGA) com antígenos dos vírus artrite encefalite caprina (CAE)/Maedi-Visna. Entre as 369 amostras de caprinos, 7(1,89\%) $(0,8-3,9 \%)$ eram soropositivas, e, entre as 383 de ovinos, $1(0,26 \%)$ $(0,0-1,4 \%)$ estava infectada. Os 7 caprinos soropositivos procederam dos abatedouros públicos dos municípios de Gravatá ( $\mathrm{n}=2)$, Sertânia $(n=4)$ e Timbaúba $(n=1)$, e o ovino soropositivo veio do abatedouro público de Serra Talhada. A soroprevalência da infecção por LVPR em pequenos ruminantes oriundos de abatedouros do estado de Pernambuco, de 1,06\% (8/752), é considerada baixa.

PALAVRAS-CHAVE: lentiviroses; epidemiologia; prevalência; artrite encefalite caprina; Maedi-Visna.

\begin{abstract}
The prevalence of lentivirus infection of small ruminants (LVPR) was determined in samples of serum from goats and sheep in slaughterhouses from ten districts of Pernambuco State. The serological test was used in agarose gel immunodiffusion (AGID) with antigen caprine arthritis and encephalitis virus (CAE)/Maedi Visna virus. Among the 369 blood serum samples of goats examined, seven (1.89\%) (0.8-3.9\%) were seropositive, and among the 383 sheep samples examined, just one $(0.26 \%)$ $(0.0-1.4 \%)$ was infected. The seven seropositive goats came from public slaughterhouses from Gravatá $(n=2)$, Sertânia $(n=4)$ and Timbaúba $(n=1)$, and the soropositive sheep was from a public slaughterhouse of Serra Talhada. The soroprevalence of LVPR infection in small ruminants from Pernambuco's slaughterhouses, of $1.06 \%(8 / 752)$, is considered low.
\end{abstract}

KEYWORDS: lentiviruses; epidemiology; prevalence; caprine arthritis encephalitis; Maedi-Visna.

'Agência de Defesa e Fiscalização Agropecuária de Pernambuco (ADAGRO) - Recife (PE), Brasil. 
Os lentivírus de pequenos ruminantes (LVPR), vírus da artrite encefalite caprina (CAEV) e vírus da Maedi-Visna (MVV), que acometem caprinos e ovinos, pertencem à família Retroviridae e subfamília Lentiviridae (CASTRO et al., 1999; SHAH et al., 2004). Esses agentes caracterizam-se por apresentarem período de incubaçáo longo, que varia de meses a anos; evoluçáo geralmente crônica, com agravamento progressivo das lesóes; perda de peso; e debilidade até a morte (NARAYAN; CoRK, 1985; CALLADO et al., 2001).

No Brasil, vários relatos indicaram a infecção por LVPR em diversos estados. Em Pernambuco, levantamentos soroepidemiológicos da infecção pelo CAEV em rebanhos caprinos demonstraram frequência de $17,7 \%$ (38/214) e 17,6\% (70/397) de positivos (Castro et al., 1994; Saraiva Neto et al., 1995), e da infecção pelo MVV em ovinos, frequência de 1,1\% (6/558) de positivos (DA Costa et al., 2007). Existem ainda dois inquéritos sorológicos dos LVPR em abatedouros do estado de Pernambuco que encontraram frequência de $3,8 \%(25 / 672)$ e $5,2 \%(17 / 325)$ de caprinos e ovinos positivos respectivamente (Oliveira et al., 2006) e 3,9\% (3/76) de caprinos positivos (CASTRo et al., 2002).

Com base nessas poucas referências, verificou-se a necessidade da realização de uma investigação soroepidemiológica mais abrangente sobre a prevalência dos LVPR em abatedouros das três regióes geográficas (sertão, agreste e zona da mata) de Pernambuco. Dessa forma, o presente trabalho teve como objetivo determinar a soroprevalência da infecção por LVPR em caprinos e ovinos provenientes de abatedouros do estado de Pernambuco.

Este estudo fez parte das atividades e metas do Centro Colaborador de Caprino e Ovinocultura para o Ministério da Agricultura, Pecuária e Abastecimento (MAPA), projeto de saúde animal desenvolvido em parceria com o Departamento de Medicina Veterinária da Universidade Federal Rural de Pernambuco (UFRPE), o MAPA, a Agência de Defesa e Fiscalização Agropecuária de Pernambuco (ADAGRO) e demais agências de Defesa Sanitária Animal do Nordeste. Todos os procedimentos foram aprovados pela Comissão de Bioética da Universidade Federal de Pernambuco (UFPE), Recife, PE, licença n. ${ }^{\circ}$ 041/2015.

Para o cálculo da prevalência dos animais nos abatedouros, o número de estabelecimentos a serem amostrados foi definido por meio da fórmula para amostragem simples aleatória com os parâmetros de prevalência de $50 \%$, precisão de $10 \%$ e nível de significância de $95 \%$ seguido do cálculo de correçấo (Thrusfield, 2004), sendo utilizados dez estabelecimentos com serviço de inspeção veterinária. O planejamento amostral para os pequenos ruminantes visou estimar o número mínimo de caprinos e ovinos a serem examinados de cada abatedouro. Desse modo, para o cálculo da prevalência em animais, calculou-se esse número mínimo mediante parâmetros de probabilidade de $95 \%$ de detecção de ao menos um animal soropositivo, número total de animais na criação e número esperado de animais soropositivos encaminhados aos abatedouros, considerando a prevalência esperada de 10\% (Thrusfield, 2004).
A escolha dos animais nos abatedouros foi casual e sistemática. Para o sorteio dos abatedouros, o estado de Pernambuco foi dividido em três áreas geográficas de acordo com sua divisão política: sertáo, agreste e zona da mata. Os resultados dos pequenos ruminantes soropositivos foram calculados por frequência (\%), com o respectivo intervalo de confiança de $95 \%$ (IC95\%) com auxílio do programa Epi Info 6.0.

Assim, a populaçáo estudada foi composta de caprinos e ovinos de abatedouros de dez municípios das três regiôes geográficas: Sertão (Parnamirim, Petrolina, Serra Talhada e Sertânia), Agreste (Capoeira, Caruaru, Gravatá e Pesqueira) e Zona da Mata (Palmares e Timbaúba), sendo um com serviço de inspeção estadual e nove com serviço de inspeção estadual. Em cada abatedouro foram aplicados um questionário e uma ficha de colheita em abatedouros, com o intuito de obter as informaçôes acerca das variáveis idade, sexo, raça e fenótipo.

No período de maio de 2011 a dezembro de 2012 colheram-se amostras de sangue de 369 caprinos e 383 ovinos por venopunçâo da jugular com agulhas descartáveis acopladas em adaptadores apropriados aos tubos de colheita a vácuo de $10 \mathrm{~mL}$, devidamente esterilizados e identificados. Após a colheita, as amostras foram mantidas em temperatura ambiente e refrigeradas até a coagulação e retração do coágulo. Posteriormente, elas foram centrifugadas por $5 \mathrm{~min}$ a $1.500 \mathrm{~g}$, e transferiram-se os soros para microtubos de polipropileno de $1,5 \mathrm{~mL}$, que foram mantidos congelados a $-20^{\circ} \mathrm{C}$ até a realização dos testes sorológicos.

Entre os 369 caprinos amostrados, com relação ao sexo, 163 eram fêmeas e 206 eram machos. Quanto aos ovinos, 148 eram fêmeas e 235 machos. A idade dos animais foi determinada conforme preconiza JARDIM (1974): os incisivos são os dentes mais importantes para a avaliação da idade e o nascimento dos dentes incisivos caducos (dentes de leite), classificados como pinças, primeiros médios, segundos médios e cantos, ocorre até a quarta semana de vida e suas mudas definitivas entre 14 e 19 meses para as pinças, 18 e 22 meses para os primeiros médios, 20 e 25 meses segundos médios, e os cantos de 25 a 31 meses. Classificaram-se as idades dos animais neste estudo pela evoluçáo dos referidos dentes. Entre os pequenos ruminantes do estudo, seis eram dente de leite com idades entre 6 meses e 1 ano; 254 eram de primeira muda; 137 de segunda muda; 76 de terceira muda; e 279 tinham dentição completa.

Considerando o grupo genético, dez caprinos eram mestiços, 358 sem raça definida (SRD) e um era Saanen. Nos ovinos, 14 eram mestiços, 338 eram SRD e 31 eram Santa Inês.

Para detecção de anticorpos precipitantes, foi empregada a imunodifusão em gel de agarose (micro-IDGA), com antígeno p28 de CAEV/Maedi-Visna, de acordo com o fabricante (Biovetech ${ }^{\circ}$, Recife, Brasil).

Entre as 369 amostras de soros sanguíneos caprinos examinados, sete $(1,89 \%)(0,8-3,9 \%)$ foram soropositivas, sendo cinco fêmeas e dois machos: dois de primeira muda; três de segunda muda; e dois tinham dentição completa todos SRD. Entre as 383 amostras de soros sanguíneos ovinos 
examinados, uma $(0,26 \%)(0,0-1,4 \%)$ foi soropositiva, um macho com dentição completa e SRD (Tabela 1).

Os sete caprinos soropositivos foram procedentes dos abatedouros públicos de Gravatá ( $n=2)$, Sertânia $(n=4)$ e Timbaúba $(\mathrm{n}=1)$, e o único ovino soropositivo veio do abatedouro público de Serra Talhada (Tabela 2).
No estado de Pernambuco, Oliveira et al. (2006) pesquisaram anticorpos contra LVPR em 627 caprinos e 325 ovinos em dois abatedouros dos municípios de São Lourenço da Mata e Paulista de Pernambuco. Os autores também encontraram frequência baixa de soropositivos (3,8\% dos caprinos e $5,2 \%$ dos ovinos), contudo maior do que a do presente estudo.

Tabela 1. Distribuição de frequência de caprinos e ovinos soropositivos à imunodifusão em gel de agarose para lentivírus de pequenos ruminantes de acordo com sexo, idade e grau de sangue/raça no estado do Pernambuco.

\begin{tabular}{|c|c|c|c|}
\hline \multirow{2}{*}{ Fator } & \multicolumn{2}{|c|}{ Resultado da micro-IDGA } & \multirow{2}{*}{ Total (\%) } \\
\hline & Caprinos (\%) & Ovinos (\%) & \\
\hline \multicolumn{4}{|l|}{ Sexo } \\
\hline Fêmea & $5 / 163(3,07)$ & $0 / 148$ & $5 / 311(1,61)$ \\
\hline Macho & $2 / 206(0,97)$ & $1 / 235(0,43)$ & $3 / 441(0,68)$ \\
\hline \multicolumn{4}{|l|}{ Muda (idade em meses) } \\
\hline Dente de leite (até 12 ) & $0 / 6$ & - & $0 / 6$ \\
\hline Primeira (16) & $2 / 77(2,6)$ & $0 / 177$ & $2 / 254(0,79)$ \\
\hline Segunda (23) & $3 / 67(4,48)$ & $0 / 70$ & $3 / 137(2,19)$ \\
\hline Terceira (29) & $0 / 42$ & $0 / 34$ & $0 / 76$ \\
\hline Quarta (40 meses) & $2 / 177(1,13)$ & $1 / 102(0,98)$ & $3 / 279(1,08)$ \\
\hline \multicolumn{4}{|l|}{ Grau de sangue } \\
\hline SRD & $7 / 358(1,96)$ & $1 / 335(0,29)$ & $8 / 693(1,15)$ \\
\hline Mestiço & $0 / 10$ & $0 / 14$ & $0 / 24$ \\
\hline Saanen & $0 / 1$ & - & $0 / 1$ \\
\hline Santa Inês & - & $0 / 31$ & $0 / 31$ \\
\hline Total & $7 / 369(1,89)$ & $1 / 383(0,29)$ & $8 / 752(1,06)$ \\
\hline
\end{tabular}

Micro-IDGA: imunodifusão em gel de agarose; SRD: sem raça definida.

Tabela 2. Distribuição de frequência de caprinos e ovinos soropositivos à imunodifusão em gel de agarose para lentivírus de pequenos ruminantes de acordo com a região e o município de origem.

\begin{tabular}{|c|c|c|c|c|c|}
\hline \multirow{2}{*}{ Região } & \multirow{2}{*}{ Abatedouro } & \multirow{2}{*}{ Inspeção } & Caprinos & Ovinos & Total \\
\hline & & & Positivos/total (\%) & Positivos/total (\%) & Positivos/total (\%) \\
\hline \multirow{4}{*}{ Sertão } & Parnamirim & Estadual & $0 / 10$ & $0 / 14$ & $0 / 24$ \\
\hline & Petrolina & Municipal & $0 / 131$ & $0 / 237$ & $0 / 368$ \\
\hline & Serra Talhada & Municipal & $0 / 80$ & $1 / 50(2)$ & $1 / 130(0,77)$ \\
\hline & Sertânia & Municipal & $4 / 80(5)$ & $0 / 30$ & $4 / 110(3,64)$ \\
\hline Subtotal & & & $4 / 301(1,33)$ & $1 / 331(0,3)$ & $5 / 632(0,79)$ \\
\hline \multirow{4}{*}{ Agreste } & Capoeiras & Municipal & $0 / 13$ & - & $0 / 13$ \\
\hline & Caruaru & Municipal & $0 / 6$ & $0 / 2$ & $0 / 8$ \\
\hline & Gravatá & Municipal & $2 / 18(11,11)$ & $0 / 26$ & $2 / 44(4,55)$ \\
\hline & Pesqueira & Municipal & $0 / 21$ & $0 / 8$ & $0 / 29$ \\
\hline Subtotal & & & $2 / 58(3,45)$ & $0 / 36$ & $2 / 94(2,13)$ \\
\hline \multirow{2}{*}{ Zona da Mata } & Palmares & Municipal & $0 / 3$ & $0 / 12$ & $0 / 15$ \\
\hline & Timbaúba & Municipal & $1 / 7(14,29)$ & $0 / 4$ & $1 / 11(9,09)$ \\
\hline Subtotal & & & $1 / 10(10)$ & $0 / 16$ & $1 / 26(3,85)$ \\
\hline Total & 10 & $\begin{array}{l}1 \text { estadual e } \\
9 \text { municipais }\end{array}$ & $7 / 369(1,89)$ & $1 / 383(0,26)$ & $8 / 752(1,06)$ \\
\hline
\end{tabular}


Também não observaram diferenças quanto à positividade, de acordo com o sexo, a faixa etária e a raça, em nenhuma das duas espécies averiguadas. Ainda em Pernambuco, no abatedouro de Carpina, a ocorrência de LVPR em caprinos SRD foi de 3,95\% (3/76), enquanto em abatedouros da Paraíba foi de 3,1\% (6/194) (CASTRO et al., 2002) e nos da regiáo metropolitana de Fortaleza 4,93\% (11/223) de ovinos soropositivos (ARAújo et al., 2004).

A realização desses estudos epidemiológicos em abatedouros é de grande valia, pois eles são uma importante fonte de dados epidemiológicos de animais, principalmente destinados à produção de carne e pele. A baixa ocorrência pode se dar por conta de os animais do estudo serem originários de criaçóes de aptidão cárnea, nas quais geralmente o manejo é menos intenso, além da grande quantidade de animais mestiços e SRD, assim como verificado por Lima et al. (2013) em inquérito sorológico utilizando caprinos $\mathrm{SRD}$, de baixa produtividade e baixo índice de tecnificação, visando sobretudo à obtençáo de carne da regiáo do Baixo Médio Sáo Francisco, Bahia. Investigaçôes de CAEV em rebanhos de leite apresentam ocorrência maior de animais soropositivos de maneira especial quando se trata de raças puras (Saraiva Neto et al., 1995; Melo; Franke, 1997; Lilenbaum et al., 2007).

Da mesma forma, a evidência de caprinos e ovinos soropositivos para LVPR nos abatedouros dos municípios de Gravatá, Sertânia, Timbaúba e Serra Talhada de cada região geográfica (Sertáo, Agreste e Zona da Mata) demonstra que nessas regióes existem criaçóes de pequenos ruminantes com ocorrência de LVPR. Ressalta-se a importância de trabalhos de extensão rural e educação sanitária aos criadores de caprinos e ovinos com o intuito de prevenir e controlar os LVPR.

| | | | | | | | | | | | | | | | | | | | | | | | | | | | | | | | | | | | | | | | | | | | | | | | | | | | | | | | | | | | | | | | | | | | | | | | | | | | | | | | | | | | | | | | | | | | | | | | | | | | | | | | | | | | | | | | | | | | | | | | | | | | | | | | | | | | | | | | | | | | | | | | | | | | | | | | | | | | | | | | | | | | | | | | | | | | | | | | | | | | | | | | | | | | | | | | | | | | | | | | | | | | | | | | | | | | | | | | | | REFERÊNCIAS

ARAÚJO, S.A.C.; DANTAS, T.V.M.; SILVA, J.B.A.; RIBEIRO, A.L.; RICARTE, A.R.F.; TEIXEIRA, M.F.S. Identificação do Maedi-Visna vírus em pulmão de ovinos infectados naturalmente. Arquivos do Instituto Biológico, v.71, n.4, p.431-436, 2004.

CALLADO, A.K.C.; CASTRO, R.S.; TEIXEIRA, M.F.S. Lentivírus de pequenos ruminantes (CAEV e Maedi-Visna): revisão e perspectivas. Pesquisa Veterinária Brasileira, v.21, n.3, p.8797, 2001. DOI: 10.1590/SO100-736X2001000300001

CASTRO, R.S.; AZEVEDO, E.O.; TABOSA, I.; NASCIMENTO, S.A.; OLIVEIRA, M.M.M. Anticorpos para o vírus da artrite-encefalite caprina em animais sem raça definida (SRD) de abatedouros dos estados de Pernambuco e Paraíba. Ciência Veterinária nos Trópicos, v.5, n.2/3, p.121-123, 2002.

CASTRO, R.S.; GREENLAND, T.; LEITE, R.C.; GOUVEIA, A.; MORNEX, J.F; CORDIER, G. Conserved sequence motifs involving the tat reading frame of Brazilian caprine lentiviruses indicate affiliations to both caprine arthritis-encephalitis virus and visna-maedi virus. Journal General Virology, v.80, n.7, p.1583-1589, 1999. DOI: 10.1099/0022-1317-80-7-1583

CASTRO, R.S.; NASCIMENTO, S.A.; ABREU, S.R.O. Evidência sorológica da infecção pelo vírus da artrite-encefalite caprina em caprinos leiteiros no estado de Pernambuco. Arquivo Brasileiro de Medicina Veterinária e Zootecnia, v.46, p.57 1-572, 1994.

DA COSTA, L.S.P.; LIMA, P.P.; CALLADO, A.K.C.; NASCIMENTO, S.A.; CASTRO, R.S. Lentivírus de pequenos ruminantes em ovinos Santa Inês: isolamento, identificação pela PCR e inquérito sorológico no estado de Pernambuco. Arquivos do Instituto Biológico, v.74, n. 1, p. 11-16, 2007.

JARDIM, W.R. Criação de caprinos. São Paulo: Nobel, 1974. 240 p.

LILENBAUM, W.; SOUZA, G.N.; RISTOW, P.; MOREIRA, M.C.; FRÁGUAS, S.; CARDOSO, V.S.; OELEMANN, W.M.R. A serological study on Brucella abortus, caprine arthritis-encephalitis virus and Leptospira in dairy goats in Rio de Janeiro, Brazil. The Veterinary Journal, v.173, n.2, p. 408-412, 2007. DOI: 10.1016/j.tvjl.2005.12.003
LIMA, C.V.V.; COSTA, J.N.; SOUZA, T.S.; MARTINEZ, P.; COSTA NETO, A.O.C.; ANUNCIAÇÃO, A.V.M.; ALMEIDA, M.G.A.R.; ARAÚJO, B.R.; PINHEIRO, R.R. Inquérito soroepidemiológico do lentivírus caprino e perfil das criações de caprinos na região do Baixo Médio São Francisco (BA). Arquivos do Instituto Biológico, v.80, n.3, p. 288-296, 2013. DOI: 10.1590/ S1808-16572013000300005

MELO, A.C.M.; FRANKE, C.R. Soroprevalence of the Caprine Arthritis Encephalitis Virus infection in dairy goats in the region of "Grande Fortaleza", Ceará, Brazil. Ciência Rural, v.27, n.1, p.113-117, 1997. DOI: 10.1590/ SO $103-84781997000100019$

NARAYAN, O.; CORK, L.C. Lentiviral diseases of sheep and goats: Chronic pneumonia, leukoencephalomyelitis and arthritis. Review of Infectious Diseases, v.7, n. 1, p.89-98, 1985.

OLIVEIRA, M.M.M.; CASTRO, R.S.; CARNEIRO, K.L.; NASCIMENTO, S.A.; CALLADO, A.K.C.; ALENCAR, C.S.A.; COSTA, L.S.P. Anticorpos contra lentivírus de pequenos ruminantes em caprinos e ovinos em abatedouros do estado de Pernambuco. Arquivo Brasileiro de Medicina Veterinária e Zootecnia, v.58, n.5, p.947-949, 2006. DOI: 10.1590/SO102-09352006000500035

SARAIVA NETO, A.O.; CASTRO, R.S.; BIRGEL, E.H.; NASCIMENTO, S.A. Estudo soro-epidemiológico da artrite-encefalite caprina em Pernambuco. Pesquisa Veterinária Brasileira, v.15, p.121124, 1995.

SHAH, C.; HUDER, J.B.; BÖNI, J.; SCHÖNMANN, M.; MÜHLHERR, J.; LUTZ, H.; SCHÜPBACH, J. Phylogenetic analysis and reclassification of caprine and ovine lentiviruses based on 104 nex isolates: evidence for regular sheep-to-goat transmission and word propagation through liverstock trade. Virology, v.319, n.1, p.12-26, 2004. DOI: $10.1016 / \mathrm{j}$. virol.2003.09.047

THRUSFIELD, M. Epidemiologia veterinária. 2a. ed. São Paulo: Roca, 2004. 556p. 